\title{
PENGGUNAAN MEDIA INTERNET DENGAN MOTIF KREATIF DAN HUBUNGANNYA DENGAN KARAKTER PESERTA DIDIK
}

\author{
Edy Sofyan', Ernandia Pandikar² \\ 1,2STKIP Pasundan \\ 1'kangedysofyan@gmail.com, 2adhie.pandikar@gmail.com
}

\begin{abstract}
The internet can have a positive impact on its users if its use is based on good values and ethics. However, at this time there has been a tendency to ignore values and ethics by Internet users because Internet media users can browse whatever they want and will experience realities beyond what they do everyday so they tend to ignore the existing character structures, value systems and norms. agreed upon in the community. The general objective to be achieved in this study is to describe and analyze the relationship between the use of internet media and creative motives for the character of students in public high schools in Bandung. The approach used in this research is a quantitative approach with a survey method. The population is students of class XI SMA Negeri in the city of Bandung. Determination of the research sample using multi stage random sampling as many as 159 students. Data collection used a questionnaire and analyzed using correlation and regression analysis. Based on data processing and analysis, research results that describe; There is a relationship between the use of internet media and creative motives on the character of students by $31.1 \%$, while the rest is influenced by other factors which are not examined in this study. The use of internet media with creative motives has a positive relationship and influence on efforts to build the character of students in schools, so it is recommended that civic education teachers need to direct and guide students to be wiser in using internet media.
\end{abstract}

Keywords: Creative Motives, Character

\begin{abstract}
ABSTRAK
Internet dapat memberikan dampak positif kepada penggunanya apabila pemanfaatannya didasarkan pada nilai dan etika yang baik. Namun, saat ini telah terjadi kecenderungan pengeyampingan nilai-nilai dan etika oleh pengguna internet karena pengguna media Internet dapat menelusuri apa saja yang diinginkannya dan akan mengalami realitas di luar apa yang dijalani sehari-hari sehingga cenderung mengabaikan tatanan karakter, sistem nilai dan norma yang telah disepakati dalam masyarakat. Tujuan umum yang ingin dicapai dalam penelitian ini adalah mendeskripsikan dan menganalisis hubungan penggunaan media internet dengan motif kreatif terhadap karakter peserta didik Sekolah Menengah Atas Negeri di Kota Bandung. Pendekatan yang digunakan dalam penelitian ini yaitu pendekatan kuantitatif dengan metode survei. Populasinya adalah peserta didik kelas XI SMA Negeri di kota Bandung. Penentuan sampel penelitian secara multi stage random
\end{abstract}


sampling sebanyak 159 Peserta didik. Penjaringan data menggunakan kuesioner dan dianalisis menggunakan analisis korelasi dan regresi. Berdasarkan pengolahan dan analisis data diperoleh hasil penelitian yang menggambarkan ; ada hubungan penggunaan media internet dengan motif kreatif terhadap karakter peserta didik sebesar $31,1 \%$ sedangkan sisanya dipengaruhi oleh faktor lain yang tidak dikaji dalam penelitian ini. Penggunaan media internet dengan motif kreatif memiliki hubungan dan pengaruh positif terhadap upaya pembinaan karakter peserta didik di sekolah, sehingga direkomendasikan agar guru pendidikan kewarganegaraan perlu mengarahkan dan membimbing peserta didik agar dapat lebih bijaksana dalam penggunaan media internet.

Kata Kunci : Motif Kreatif, Karakter

\section{A. Pendahuluan}

Pembangunan karakter bangsa sudah diupayakan dengan berbagai bentuk seperti melalui pendidikan formal maupun nonformal. Namun, sampai saat ini belum terlaksana dengan optimal sehingga terjadi maraknya penyimpanganpenyimpangan perilaku yang dilakukan oleh anak bangsa, baik itu remaja maupun dewasa.

Penyimpangan-penyimpangan

tersebut dilakukan hampir dapat ditemui disemua kalangan masyarakat, mulai dari pelajar, mahasiswa, pegawai swasta, pegawai negeri, pejabat negara dan lain-lain. Pembangunan karakter tidak hanya tanggung jawab pemerintah, pendidik, keluarga, dan masyarakat tetapi media massa sebagai salah satu sarana yang efektif juga bertanggung jawab terhadap pendidikan karakter mengingat penyimpanganpenyimpangan yang terjadi tidak sedikit dari pengaruh media seperti video porno. Hal tersebut sesuai dengan pendapat Dadang Hawari dalam Yusuf Syamsu, (2008: 36-37) bahwa : perubahan-perubahan yang serba cepat sebagai konsekuensi globalisasi, modernisasi, industrialisasi, dan IPTEK telah mengakibatkan pada perubahan nilainilai sosial dan budaya. Perubahan ini antara lain pada nilai moral, etika, kaidah agama dan pendidikan anak di rumah, pergaulan, dan perkawinan. Perubahan ini muncul karena pada masyarakat terjadi pergeseran pola 
hidup yang bercorak social religious ke pola individual matrealistis dan sekuler. Salah satu dampaknya perubahan itu adalah terancamnya lembaga perkawinan yang merupakan lembaga pendidikan dini bagi anak dan remaja. Demikian pulan pola hidup konsumtif telah mewarnai kehidupan anak dan remaja di perkotaan, yang dampaknya adalah kenakalan remaja, penyalahgunaan narkotika, alkohol dan zat adiktif lainnya.

Pembangunan karakter harus terus dilakukan tanpa mengesampingkan perkembangan ilmu pengetahuan dan teknologi untuk mewujudkan warga negara yang berspektif global bertindak lokal. Hal ini sesuai dengan pendapat Naisbitt (1990: 68) bahwa warga negara dalam era globalisasi saat ini harus "think globally act locally. Lebih lanjut, Wahab memperjelas dalam konteks Indonesia bahwa dalam era globalisasi saat ini diperlukan warga negara Indonesia yang senantiasa berpikir global, refleksi nasional dan bertindak lokal (Wahab, 1996: 27).
Sedangkan, teori tentang Cultural Lag atau ketertinggalan budaya dari Ogburn bahwa pertumbuhan atau perubahan unsur kebudayaan yang mengalami perubahan tidak sama cepatnya yaitu kecenderungan dari kebiasaankebiasaan sosial dan pola-pola organisasi sosial yang tertinggal di belakang perubahan kebudayaan materiil (Supardan, 2008: 157). Ketidakseimbangan perubahan antara budaya material dan immaterial itulah yang disebut dengan ketertinggalan budaya. Media internet sebagai budaya materiil lebih cepat perubahannya sedangkan tata krama sebagai unsur budaya immaterial lebih lambat perubahannya sehingga terpengaruh terhadap perkembangan budaya materiil. Diperkuat oleh pendapat Kenichi Ohmae dalam bukunya yang berjudul Borderless World: Power and Strategy in the Interlinked Economy (1996) dan The End of Nation State : The Rise of Regional Economies

(1996), (Budimansyah, 2010: 9-10) mengatakan bahwa dalam 
perkembangan masyarakat global, batas-batas wilayah negara dalam arti geografis dan politik relatif masih tetap. Namun kehidupan dalam suatu negara tidak mungkin dapat membatasi kekuatan global yang berupa informasi, inovasi, dan industri yang membentuk peradaban modern.

Menurut (Giddens, 1990) Perlu di catat bahwa proses globalisasi tidak berbasis pada kekuatan tunggal secara terpisah, seperti kapitalisme, teknologi informasi komunikasi, kapitalisme, militerisme, sistem negara-bangsa dan pembagian kerja internasional. (Kalidjernih,2007) Globalisasi merupakan perkembangan kontemporer yang mempunyai pengaruh dalam mendorong munculnya berbagai kemungkinan tentang perubahan dunia yang akan berlangsung. Pengaruh globalisasi dapat menghilangkan berbagai halangan dan rintangan menjadikan dunia semakin terbuka dan saling bergantung satu sama lain. Semua orang menyadari bahwa sekarang ini proses dan pengaruh globalisasi makin dirasakan sebagai bagian dari kehidupan manusia (Purnamasari, 2010:1). Namun, hingga kini dampak negatif semakin meningkat terutama terkait dengan tatanan karakter yang mana banyak perilaku warga negara yang menyimpang dari nilai-nilai, karakter dan norma. Hal ini sesuai dengan pendapat Djahiri (2006: 13), dalam kehidupan dan generasi inilah keberadaan tatanan norma dengan perangkat nilai karakter luhur goyah, tergeser dan atau tergusur.

Menurut Djahiri (2006: 11)“Iptek telah melahirkan temuan konsep/dalil dan produk baru yang serba elektronik - masal meninggalkan ketergantungan manusia dan kehidupannya terhadap tenaga manusia, binatang, dan alam serta memperpendek jarak waktu antar space".

Hal ini nampak dengan munculnya berbagai media yang digunakan untuk berkomunikasi, salah satunya adalah media internet. Internet adalah jaringan komputer yang terhubung secara internasional dan tersebar di seluruh dunia yang 
memungkinkan setiap orang berkomunikasi dengan orang lain yang berada di negara lain atau tempat yang jauh tanpa mengenal batas dan waktu. Pada tataran individu dalam hal ini peserta didik, orang yang menggunakan internet akan mengalami realitas di luar apa yang dijalaninya sehari-hari. Pada titik tertentu orang-orang yang mengakses teknologi informasi dengan fasilitas komunikasi via internet misalnya, menjadi tidak peduli dengan tatanan karakter, sistem nilai dan norma yang telah disepakati dalam masyarakat selama berabad-abad yang tidak lagi peduli pada aturan yang ada. Beberapa tahun terakhir sejak internet menjadi media yang paling diminati oleh masyarakat dunia, banyak sekali kasus-kasus yang muncul sehubungan dengan penggunaan media ini.

Sebaliknya, sejarah juga mencatat kontribusi positif internet. Sedangkan dari sisi ilmu pengetahuan, khsususnya terkait dengan riset ilmiah, internet memberikan sumbangan yang sangat besar, terutama berkaitan dengan pengurangan personel pengambilan data, biaya untuk mengurangi perjalanan fisik, dan penghematan waktu. Selain server-server yang menyediakan data sekunder, komunitas-komunitas dunia maya merupakan sumber penyedia responden untuk mendapatkan data primer dengan lebih cepat, mudah, dan biaya lebih murah. Oleh karena itu, perlu adanya pendidikan karakter yang dilakukan oleh media agar tidak terjadi peningkatan penyimpangan karakter dan akhlak pada berbagai kalangan masyarakat mengakibatkan kemerosotan karakter. Menurut Desain Induk Pembangunan Karakter Bangsa Pemerintah Republik Indonesia tahun 2010-2025 (2010:2) akan terjadi : 1) disorientasi dan belum dihayati nilai-nilai Pancasila sebagai filosofi dan ideologi bangsa; 2) keterbatasan perangkat kebijakan terpadu dalam mewujudkan nilai-nilai esensi Pancasila; 3) bergesernya nilai etika dalam kehidupan berbangsa dan bernegara; 4) memudarnya kesadaran terhadap nilai-nilai budaya 
berbangsa dan bernegara; 5) ancaman disintegrasi bangsa, dan 6) melemahnya kemandirian bangsa. Selain itu, akan terjadi kejahatan dan demoralisasi umat manusia yang mana beberapa indikator yang digunakan kemudian dijadikan ukuran bagi perkembangan kualitas kehidupan suatu bangsa. Lebih lanjut, menurut Lickona (1992: 53) terdapat sepuluh tanda dari perilaku manusia yang menunjukkan arah kehancuran suatu bangsa yaitu: meningkatnya kekerasan di kalangan remaja, ketidakjujuran yang membudaya, semakin tingginya rasa tidak hormat kepada orangtua, guru dan figur pemimpin, pengaruh peer group terhadap tindakan kekerasan, meningkatnya kecurigaan dan kebencian, penggunaan bahasa yang memburuk, penurunan etos kerja, menurunnya rasa tanggungjawab individu dan warga negara, meningginya perilaku merusak diri dan semakin kaburnya pedoman karakter. Karakter bangsa Indonesia yang sebelumnya berpegang pada ajaran-ajaran agama, nilai-nilai luhur bangsa terus mengalami kemerosotan secara cepat. Namun, berbagai bentuk pelanggaran itu dengan segera dan instan menyebar melalui media komunikasi instan seperti internet.

Pada saat ini nampaknya telah terjadi kecenderuangan pengguna internet yang kerap mengeyampingkan nilai-nilai dan karakter etika padahal dalam tatanan sosial, etika sangat diperlukan guna menghindari terjadinya pergesekan yang berujung konflik. Selain itu juga warga negara muda Indonesia dengan tiadanya unsur ini menyebabkan manusia Indonesia terombang-ambing, lemah karsa, mudah diarahkan pada hal-hal yang "bengkok" (Soewardi, 2005:138).

Kondisi watak atau "karakter" manusia umumnya dewasa ini, sejak dari level internasional sampai kepada tingkat personal individual, khususnya bangsa kita, kelihatan mengalami berbagai disorientasi dan kemerosotan. Bagi sebagian warga negara dalam hal ini peserta didik menggunakan dan mengekplorasi 
media internat dianggap sebagai sebuah cara untuk mengetahui perubahan gaya hidup modern. Seorang dikatakan modern apabila bisa mengikuti mode-mode atau gaya hidup yang banyak di gunakan oleh masyarakat moderen. Di sisi lain, kegemaran mengunakan internet memiliki dampak terhadap perilaku dan karakter peserta didik jika intensitas menggunakan internet dengan motif yang digemarinya, seorang remaja cenderung akan menghabiskan waktunya bahkan menyita waktu belajarnya.

Penggunaan internet dikalangan peserta didik tidak hanya dilakukan untuk kepentingan yang menunjang kegiatan akademiknya, akan tetapi beragam motif penggunaannya sebagai kebutuhan manusia dalam mengaktualisasikan diri. Hal tersebut sesuai dengan pendapat Menurut Mc Clelland (1961), menyatakan bahwa ada tiga hal penting yang menjadi kebutuhan manusia, yaitu: need for achievement (kebutuhan akan prestasi), need for afiliation (kebutuhan akan hubungan sosial/hampir sama dengan pendapatnya Maslow), dan need for Power (dorongan untuk mengatur). Sedangkan, menurut Herbert Blumber dan Katz tidak hanya dipengaruhi teori kegunaan tetapi kepuasan juga berpengaruh. Oleh karena itu, penelitian ini penting agar di hasilkan suatu informasi yang dapat memberikan gambaran tentang hubungan penggunaan Internet dengan Motif Kreatif oleh para peserta didik sehingga dapat memberikan informasi serta pemahaman di kalangan sekolah, orang tua serta lingkungan yang pada akhirnya menjadi masukan atau berkontribusi dalam pembuatan kebijakan.

\section{B. Metode Penelitian}

Penelitian ini menggunakan pendekatan kuantitatif dengan tujuan untuk mengukur banyaknya variabel, menguji hipotesis, dan membuat kesimpulan dari pertanyaanpertanyaan mengenai perilaku, pengalaman atau karakteristik dari suatu fenomena. Dalam penelitian ini menggunakan metode survei, dengan 
teknik

kuesioner

untuk

mengumpulkan data.

\section{C.Hasil Penelitian dan Pembahasan}

Hasil penelitian ini

mengindikasikan bahwa semakin tinggi penggunaan media internet dengan motif kreatif, akan diikuti oleh meningkatnya perubahan karakter peserta didik. Hal ini dapat diterangkan oleh persamaan regresi $\hat{Y}$ $=68.913+0.789 \mathrm{X}_{1}$. Dengan persamaan regresi tersebut dapat diinterprestasikan bahwa jika penggunaan media internet dengan motif kreatif (X) dengan karakter peserta didik (Y) diukur dengan instrument yang dikembangkan dalam penelitian ini, maka setiap perubahan skor variabel penggunaan media internet dengan motif kreatif sebesar satu satuan dapat diestimasikan skor karakter peserta didik akan berubah sebesar 0.789 satuan pada arah yang sama.

Dari perhitungan korelasi antara variabel penggunaan media internet dengan motif kreatif (X) dengan karakter peserta didik (Y) tergolong sedang yaitu sebesar 0,558. ini menunjukkan antara variabel $\mathrm{X}$ dan variabel $Y$ memiliki hubungan yang berarti, meskipun korelasinya tergolong sedang. Secara empiris, hasil penelitian menginformasikan bahwa penggunaan media internet dengan motif kreatif yang dicerminkan oleh lima dimensi yaitu, (1) minat yang luas, (2) rasa ingin tahu yang besar, (3) merasa tidak puas, (4) percaya diri (5) ulet dan suka bekerja keras, berpengaruh secara signifikan dan positif terhadap karakter peserta didik. Besarnya pengaruh penggunaan media internet dengan motif kreatif terhadap karakter peserta didik pada Sekolah Menengah Atas Negeri di kota Bandung, adalah sebesar 31,1 \%. Hal tersebut sejalan dengan teori kreativitas menurut Torrance (1977) bahwa orang kreatif itu memiliki ciriciri (1) minat yang luas, (2) rasa ingin tahu yang besar, (3) merasa tidak puas, (4) percaya diri (5) ulet dan suka bekerja keras, berpengaruh secara signifikan dan positif terhadap karakter peserta didik. 


\section{E. Kesimpulan}

Berdasarkan hasil penelitian, disimpulkan bahwa Penggunaan internet dengan motif kreatif yang sebagian besar sering dilakukan adalah karena: internet menarik untuk dipelajari, mengunjungi website mengenai hal kreatif dan informatif, mengikuti perkembangan terkini melalui website serta membantu dalam pengerjaan atau penyelesaian tugas-tugas sekolah dapat mengembangkan karakter peserta didik apabila motif kreatif dalam hal positif.

\section{DAFTAR PUSTAKA}

Creswell, J.W. (2010). Research Design Qualitative \& Quantitative

Approach.Penerjemah Achmad Fawaid. Yogyakarta: Pustaka Pelajar.

Budimansyah, D.(2008) Membangun Karakter Bangsa Di Tengah Arus Globalisasi dan Gerakan Demokratisasi:Reposisi Peran Pendidikan Kewarganegaraan.
Pidato Pengukuhan guru besar tetap PPKN, IPS,IKIP.Bandung. Budimansyah, Dasim dan Suryadi, Karim . (2008). PKN dan Masyarakat Multikultural. Bandung : Program Studi Pendidikan Kewarganegaraan Universitas Pendidikan Indonesia.

Creswell, J.W. (1998). Research Design Qualitative \& Quantitative Approach. London: Publication. Djahiri, A, K, (1996), Menelusuri Dunia Afektif: Pendidikan Nilai Dan Moral, Bandung Lab. PPMP IKIP Bandung

Djahiri, A,K (2006), Budimansyah dan syaifullah (ed) Esensi Pendidikan Nilai- Moral dan PKn dalam di Era Globalisasi, 70 tahun Prof. Kosasih Djahiri, Bandung : Lab PKn UPI

Kalidjernih, Freddy Kirana.(2010), Penulisan

Akademik.Bandung:Widya

Aksara.

Koesoema , D,A (2010), Pendidikan Karakter: Startegi Mendidik Anak 
di Zaman

Global, Jakarta:

Kompas Gramedia

Nazir, Moh. (1983). Metode

Penelitian. Jakarta: Ghalia Indonesia.

Noorsyam, M, (2001), Etika

Kehidupan Bermasyarakat dan Bernegara Demi Terpeliharanya Integritas Nasionl, Jakarta: LKPBK

Pemerintah

Republik

Indonesia.(2010). Desain Induk

Pembangunan Karakter Bangsa

Tahun 2010-2025.

Prawira Budi, Triton. (2007). SPSS

13.0 Terapan; Riset Statistik

Parametrik, Yogyakarta: CV.

Andi Offset.

Sapriya. (2008). “ Persepektif

Pemikiran Pakar tentang

Pendidikan Kewarganegaraan

dalam Pembangunan Karakter

Bangsa". Jurnal Pendidikan

Kewarganegaraan. Program

studi.

Pendidikan

Kewarganegaraan. Sekolah

Pascasarjana. UPI, Volume 1,

no 2, April 2008, Hal.199-214.
Sjarkawi, (2005). Pembentukan Kepribadian Anak, Jakarta: PT. Bumi Aksara.

Sugiyono, (2003). Metode Penelitian

Administrasi Dilengkapi Dengan

Metode R\&D, Bandung:

Alfabeta.

Suryadi, A. (2009). " Pendidikan Kewarganegaraan

Menyongsong Masa Depan Bangsa". Jurnal Pendidikan Kewarganegaraan. Program studi. Pendidikan Kewarganegaraan. Sekolah Pascasarjana. UPI, Volume 3, no 1, Oktober, Hal.1-15.

Winataputra, Udin S (2001). Jati diri Pendidikan Kewarganegaraan sebagai Wahana Sistemik Pendidikan Demokrasi. Program Pascasarjana, Universitas Pendidikan Indonesia

Winataputra, Udin S dan Budimansyah, Dasim (2007). Civic Education: konteks, landasan, bahan ajar dan kultur kelas. Program Studi Pendidikan Kewarganegaraan, Sekolah 
Pascasarjana Universitas

Pendidikan Indonesia

Winatraputra, U. (2007). “ Pendidikan

Kewarganegaraan dalam

Perspektif Internasional”. Jurnal

Pendidikan Kewarganegaraan.

Program studi. Pendidikan

Kewarganegaraan. Sekolah

Pascasarjana. UPI, Volume 1,

no 1, Oktober, Hal.1-10. 